\title{
Tribo-Chemistry of Phosphonium-Derived Ionic Liquids
}

\author{
Ichiro Minami · Taketo Inada • Ryusuke Sasaki • \\ Hidetaka Nanao
}

Received: 1 April 2010/Accepted: 15 May 2010/Published online: 30 May 2010

(C) Springer Science+Business Media, LLC 2010

\begin{abstract}
The tribological properties of room temperature ionic liquids containing tetraalkylphosphonium cations were evaluated on the basis of the chemical structure of their salts. The tribochemistry of these ionic liquids was discussed on the basis of the results of tribo-tests and surface analyses. The tribological properties of the tetraalkylphosphonium salts examined in this work were observed to be better than those of 1,3-alkylimidazolium salts. The structure of the alkyl group in the phosphonium cation also has a slight effect on the tribological properties of the salts. During a friction test carried out under lowload conditions, the phosphonium cation was oxidized to phosphate to form a boundary film. This film inhibited the reaction of the bis(trifluoromethanesulfonyl)amide anion that yielded metal fluoride on the rubbed surfaces. The combination of the phosphonium cation with a phosphate anion or thiophosphate anion resulted in a better lubricant than 1,3-alkylimidazolium bis(trifluoromethanesulfonyl)amide. The reactions of the phosphate anion and thiophosphate anion yielded a phosphate boundary film that exhibited better tribological properties than those of the fluoride boundary film.
\end{abstract}

Keywords Ionic liquid - Surface chemistry · Lubricant chemistry · Tribochemistry .

Structure-property relations

\section{Abbreviations}

AES Auger electron spectroscopy

I. Minami $(\bowtie) \cdot$ T. Inada · R. Sasaki · H. Nanao

Department of Chemical Engineering, Iwate University,

4-3-5 Ueda, Morioka, Iwate 020-8551, Japan

e-mail: ichiro@iwate-u.ac.jp
$\begin{array}{ll}\mathrm{BF}_{4} & \text { Tetrafluoroborate } \\ \text { BMIM } & \text { 1-Butyl-3-methylimidazolium } \\ \mathrm{JIS} & \text { Japanese Industrial Standards } \\ \mathrm{PF}_{6} & \text { Hexafluorophosphate } \\ \mathrm{R}_{4} \mathrm{P} & \text { Tetraalkylphosphonium } \\ \text { RT-IL } & \text { Room temperature ionic liquid } \\ \text { SUJ2 } & \text { Bearing steel assigned by JIS } \\ \text { TFSA } & \text { Bis(trifluoromethanesulfonyl)amide } \\ \text { XPS } & \text { X-ray photoelectron spectroscopy }\end{array}$

\section{Introduction}

Room temperature ionic liquids (RT-ILs) have attracted considerable attention as advanced materials because of their remarkable chemical and physical properties [1-7]. In the field of tribology, the use of RT-ILs as lubricants was first reported in 2001 [8]. Since then, there have been numerous reports on similar applications have been published in international tribology journals. Thus far, the relationship between the chemical structure and the tribological properties of RT-ILs has been fundamentally studied [9-11]; it has been observed that hydrophobic anions (e.g., TFSA) afforded better tribological properties to RT-ILs than the hydrophilic anions (e.g., $\mathrm{BF}_{4}$ ) $[12,13]$. Higher alkyl groups in imidazolium cations are instrumental in improving the tribological properties of a compound. Further, hydrophobic anions afford a superior thermo-oxidative stability to RT-ILs as compared to hydrophilic ones [12,14]. The thermo-oxidative stability of RT-ILs decreases with increase in the chain length of the alkyl group in an imidazolium cation [15].

It has been estimated that numerous RT-ILs can be realized by combining anions and cations in various ways 
[16]. Various anions and cations have been developed as precursors of RT-ILs. However, in tribology, the main anions under consideration are $\mathrm{BF}_{4}, \mathrm{PF}_{6}$, and TFSA. Most literatures on cationic moieties deal with imidazolium derivatives [9]. From a chemical perspective, alkylimidazolium cations are versatile building blocks of cationic moieties having bulky and asymmetrical skeletons.

Tetraalkylphosphonium $\left(\mathrm{R}_{4} \mathrm{P}\right)$-derived RT-ILs, which have a structure analogous to tetraammonium cations, are known to exhibit better thermal stability than alkylimidazolium-derived ones [17-19]. To date, there are brief reports on the tribological properties of $\mathrm{R}_{4} \mathrm{P}$-derived $\mathrm{RT}$ ILs [13, 20-25]. In this work, we focused on the relationship between the chemical structure and tribological properties of RT-ILs. Further, we evaluated $\mathrm{R}_{4} \mathrm{P}$ salts of TFSA and phosphate-derived anions by means of laboratory tribo-tests. The tribological properties of $\mathrm{R}_{4} \mathrm{P}$-derived RT-ILs were discussed on the basis of tribochemistry.

\section{Experimental}

\subsection{Chemicals}

The structure, name, and abbreviation (code) of the ionic liquid samples used in this experiment are shown in Table 1. BMIM-TFSA was selected as the reference sample. Methoxyethyl-substituted ammonium salt $\left(\mathrm{Et}_{2} \mathrm{MeMeOEN}-\right.$

Table 1 Structure and properties of sample

\begin{tabular}{|c|c|c|c|c|}
\hline Code & Structure & IUPAC name & $T_{\mathrm{g}}\left({ }^{\circ} \mathrm{C}\right)$ & $\begin{array}{l}\text { Viscosity } \\
\text { at } 25^{\circ} \mathrm{C} \\
\left(\mathrm{mm}^{2} \mathrm{~s}^{-1}\right)\end{array}$ \\
\hline BMIM-TFSA & $\underbrace{\mathrm{N}_{3}^{\mathrm{H}}=\mathrm{N}^{-n-\mathrm{C}_{4} \mathrm{H}_{9}}}_{\left(\mathrm{CF}_{3} \mathrm{SO}_{2}\right)_{2} \mathrm{~N}^{\ominus}}$ & $\begin{array}{l}\text { 1-Butyl-3-methylimidazolium } \\
\text { bis(trifluoromethylsulfonyl)amide }\end{array}$ & -4.0 & 38.5 \\
\hline $\mathrm{Et}_{2} \mathrm{MeMeOEN-TFSA}$ & $\begin{array}{c}\mathrm{H}_{3} \mathrm{C}_{1} \oplus \\
\mathrm{C}_{2} \mathrm{H}_{5}-\mathrm{N}-\mathrm{C}_{2} \mathrm{H}_{4} \mathrm{OCH}_{3} \\
\mathrm{C}_{2} \mathrm{H}_{5}^{\prime} \\
\left(\mathrm{CF}_{3} \mathrm{SO}_{2}\right)_{2} \mathrm{~N}^{\ominus}\end{array}$ & $\begin{array}{l}\text { Diethyl(methyl)(2-methoxyethyl)ammonium } \\
\text { bis(trifluoromethylsulfonyl)amide }\end{array}$ & $<-50$ & 20.4 \\
\hline $\mathrm{Et}_{3} \mathrm{PeP}-\mathrm{TFSA}$ & $\begin{array}{c}\left(\mathrm{C}_{2} \mathrm{H}_{5}\right)_{3} \mathrm{P}\left(n-\mathrm{C}_{5} \mathrm{H}_{11}\right) \\
\left(\mathrm{CF}_{3} \mathrm{SO}_{2}\right)_{2} \mathrm{~N}^{\ominus}\end{array}$ & $\begin{array}{l}\text { Triethylpentylphosphonium } \\
\text { bis(trifluoromethylsulfonyl)amide }\end{array}$ & 17.0 & 66.7 \\
\hline $\mathrm{Et}_{3} \mathrm{OcP}-\mathrm{TFSA}$ & $\begin{array}{r}\left(\mathrm{C}_{2} \mathrm{H}_{5}\right)_{3} \mathrm{P}\left({ }^{\oplus}-\mathrm{C}_{8} \mathrm{H}_{17}\right) \\
\left(\mathrm{CF}_{3} \mathrm{SO}_{2}\right)_{2} \mathrm{~N}^{\ominus}\end{array}$ & $\begin{array}{l}\text { Triethyloctylphosphonium } \\
\text { bis(trifluoromethylsulfonyl)amide }\end{array}$ & $<-50$ & 102.4 \\
\hline $\mathrm{Et}_{3} \mathrm{DdP}-\mathrm{TFSA}$ & $\begin{array}{c}\left(\mathrm{C}_{2} \mathrm{H}_{5}\right)_{3} \mathrm{P}\left(n-\mathrm{C}_{12} \mathrm{H}_{25}\right) \\
\left(\mathrm{CF}_{3} \mathrm{SO}_{2}\right)_{2} \mathrm{~N}^{\ominus}\end{array}$ & $\begin{array}{l}\text { Triethyldodecylphosphonium bis } \\
\text { (trifluoromethylsulfonyl)amide }\end{array}$ & 13.0 & 148.8 \\
\hline $\mathrm{Et}_{3} \mathrm{BnP}-\mathrm{TFSA}$ & $\begin{array}{c}\stackrel{\oplus}{\left(\mathrm{C}_{2} \mathrm{H}_{5}\right)_{3} \mathrm{P}\left(\mathrm{CH}_{2} \mathrm{C}_{6} \mathrm{H}_{5}\right)} \\
\left(\mathrm{CF}_{3} \mathrm{SO}_{2}\right)_{2} \mathrm{~N}^{\ominus}\end{array}$ & $\begin{array}{l}\text { Triethylbenzylphosphonium bis } \\
\text { (trifluoromethylsulfonyl)amide }\end{array}$ & -67.0 & 173.4 \\
\hline
\end{tabular}


Table 1 continued

\begin{tabular}{|c|c|c|c|c|}
\hline Code & Structure & IUPAC name & $T_{\mathrm{g}}\left({ }^{\circ} \mathrm{C}\right)$ & $\begin{array}{l}\text { Viscosity } \\
\text { at } 25^{\circ} \mathrm{C} \\
\left(\mathrm{mm}^{2} \mathrm{~s}^{-1}\right)\end{array}$ \\
\hline $\mathrm{Et}_{3} \mathrm{MeOEP}-\mathrm{TFSA}$ & $\begin{array}{c}\left(\mathrm{C}_{2} \mathrm{H}_{5}\right)_{3} \mathrm{P}\left(\mathrm{C}_{2} \mathrm{H}_{4} \mathrm{OCH}_{3}\right) \\
\left(\mathrm{CF}_{3} \mathrm{SO}_{2}\right)_{2} \mathrm{~N}^{\ominus}\end{array}$ & $\begin{array}{l}\text { Triethyl(2-methoxyethyl)phosphonium } \\
\text { bis(trifluoromethylsulfonyl)amide }\end{array}$ & 14.0 & 24.6 \\
\hline $\mathrm{Bu}_{3} \mathrm{MeP}-\mathrm{TFSA}$ & $\begin{array}{c}\left(n-\mathrm{C}_{4} \mathrm{H}_{9}\right)_{3} \mathrm{P}\left(\mathrm{CH}_{3}\right) \\
\left(\mathrm{CF}_{3} \mathrm{SO}_{2}\right)_{2} \mathrm{~N}^{\ominus}\end{array}$ & $\begin{array}{l}\text { Tributylmethylphosphonium } \\
\text { bis(trifluoromethylsulfonyl)amide }\end{array}$ & 16.0 & 161.7 \\
\hline $\mathrm{Bu}_{3} \mathrm{OcP}-\mathrm{TFSA}$ & $\begin{array}{c}\left(n-\mathrm{C}_{4} \mathrm{H}_{9}\right)_{3} \mathrm{P}\left(n-\mathrm{C}_{8} \mathrm{H}_{17}\right) \\
\left(\mathrm{CF}_{3} \mathrm{SO}_{2}\right)_{2} \mathrm{~N}^{\ominus}\end{array}$ & $\begin{array}{l}\text { Tributyl octylphosphonium } \\
\text { bis(trifluoromethylsulfonyl)amide }\end{array}$ & $<-50$ & 211.9 \\
\hline $\mathrm{Bu}_{3} \mathrm{DdP}-\mathrm{TFSA}$ & $\begin{array}{c}\left({ }^{\mathrm{n}} \mathrm{C}_{4} \mathrm{H}_{9}\right)_{3} \mathrm{P}\left(n-\mathrm{C}_{12} \mathrm{H}_{25}\right) \\
\left(\mathrm{CF}_{3} \mathrm{SO}_{2}\right)_{2} \mathrm{~N}^{\ominus}\end{array}$ & $\begin{array}{l}\text { Tributyldodecylphosphonium } \\
\text { bis(trifluoromethylsulfonyl)amide }\end{array}$ & 16.0 & 268.1 \\
\hline $\mathrm{Bu}_{3} \mathrm{MeP}-\mathrm{MePhos}$ & $\begin{array}{c}\left(n-\mathrm{C}_{4} \mathrm{H}_{9}\right)_{3} \stackrel{\oplus}{\mathrm{P}\left(\mathrm{CH}_{3}\right)} \\
\left(\mathrm{CH}_{3} \mathrm{O}\right)_{2} \mathrm{P}(\mathrm{O}) \mathrm{O}^{\ominus}\end{array}$ & Tributylmethylphosphonium dimethylphosphate & 12.0 & 570.5 \\
\hline $\mathrm{Bu}_{4} \mathrm{P}$-EtTPhos & $\begin{array}{r}\left(n-\mathrm{C}_{4} \mathrm{H}_{9}\right)_{4} \mathrm{P}^{\oplus} \\
\left(\mathrm{C}_{2} \mathrm{H}_{5} \mathrm{O}\right)_{2} \mathrm{P}(\mathrm{S}) \mathrm{S}^{\ominus}\end{array}$ & $\begin{array}{l}\text { Tetrabutylphosphonium } O \\
O \text {-diethyllphosphorodithioate }\end{array}$ & $10-12$ & 1176.5 \\
\hline
\end{tabular}

TFSA) was examined as a nitrogen cation with a structure analogous to methoxyethyl-substituted phosphonium salt $\left(\mathrm{Et}_{3} \mathrm{MeOEP}-\mathrm{TFSA}\right)$. All the samples employed in the tribotests were of reagent grade and used as received.

\subsection{Tribo-Test}

The friction-reducing properties of the samples were determined using a T-type pendulum friction tester [26]. This test is conducted on a small quantity (approximately $1 \mathrm{~cm}^{3}$ ) of a sample in order to determine its friction coefficient under boundary conditions with good repeatability. Thirty tests were run for each sample and the average of friction coefficient for all test runs was reported. A ball-on-flat-type tribo-tester in a reciprocating motion was employed to evaluate the anti-wear properties of sample. Two tests were run for each set of test parameters and the average of two test runs was reported if differences in the results were $<15 \%$. After the test, the wear scar diameter of the ball and wear width on flat specimen were measured using an optical microscope. The details of the test conditions are shown in Tables 2 and 3.

\subsection{Surface Analyses}

After the ball-on-flat-type test was conducted, the resultant flat was ultrasonically cleaned in hexane and the rubbed surfaces were studied by means of Auger electron spectroscopy (AES) and X-ray photoelectron spectroscopy (XPS). The conditions of the surface analyses are shown in Tables 4 and 5. 
Table 2 Conditions of pendulum friction test

\begin{tabular}{ll}
\hline Operation parameters & \\
Applied load $(\mathrm{N})$ & 2.9 \\
Hertz contact stress $(\mathrm{GPa})$ & 1.1 \\
Initial amplitude of swing $(\mathrm{Rad})$ & 0.5 \\
Oil temperature $\left({ }^{\circ} \mathrm{C}\right)$ & $20-25$ \\
Test specimen & \\
Ball & $\mathrm{SUJ} 2(\mathrm{JIS})$ \\
Material & \\
Contents: C $(0.95-1.10 \%), \mathrm{Si}(0.15-0.35 \%)$, & \\
Mn $(<0.5 \%), \mathrm{P}(<0.025 \%), \mathrm{S}(0.025 \%)$, & 62 \\
Cr $(1.30-1.60 \%)$ and $\mathrm{Fe}(\mathrm{balance})$ & 0.040 \\
Hardness $(\mathrm{HRc})$ & 4.76 \\
Surface roughness $\mathrm{Ra}(\mu \mathrm{m})$ & \\
Diameter $(\mathrm{mm})$ & $\mathrm{SUJ} 2(\mathrm{JIS})$ \\
Pin & 62 \\
Material & 0.040 \\
Hardness $(\mathrm{HRc})$ & $\phi 2 \times 30$ \\
Surface roughness $\mathrm{Ra}(\mu \mathrm{m})$ & \\
Size of pin $(\mathrm{mm})$ &
\end{tabular}

Table 3 Conditions of ball-on-flat-type tribo-test

\begin{tabular}{ll}
\hline Operation parameters & \\
Applied load $(\mathrm{N})$ & $10-60$ \\
Hertz contact stress $(\mathrm{GPa})$ & $1.33-2.41$ \\
Hertz deformation indentation $(\mathrm{mm})$ & $1.20-2.18 \times 10^{-1}$ \\
Frequency $(\mathrm{Hz})$ & 1.0 \\
Amplitude $(\mathrm{mm})$ & 5.0 \\
Oil temperature $\left({ }^{\circ} \mathrm{C}\right)$ & $20-25$ \\
Test duration $(\mathrm{min})$ & 30 \\
Test specimen & \\
Ball & \\
Material & SUJ2 (JIS) \\
Diameter $(\mathrm{mm})$ & 6.35 \\
Hardness $(\mathrm{HRc})$ & 62 \\
Surface roughness Ra $(\mu \mathrm{m})$ & 0.040 \\
Flat & \\
Material & SUJ2 (JIS) \\
Size (mm) & $\phi 25 \times 7$ \\
Hardness $(\mathrm{HRc})$ & 62 \\
Surface roughness Ra $(\mu \mathrm{m})$ & 0.030 \\
\hline
\end{tabular}

\section{Results and Discussion}

\subsection{Determination of Friction Coefficient Using Pendulum Friction Test}

The preliminary results of the pendulum friction test were obtained in order to determine the friction-reducing
Table 4 Conditions of XPS analysis

\begin{tabular}{ll}
\hline Instrument & PHI instruments Quantum-2000 \\
\hline X-ray source & Monochromated Al K ${ }_{\alpha}$ ray \\
& $(1486.6 \mathrm{eV}) 40 \mathrm{~W}$ \\
Test area $(\mathrm{mm})$ & $\phi 200 \mu \mathrm{m}$ ellipse \\
Emission angle $\left(^{\circ}\right)$ & 45 \\
Depth of analysis $(\mathrm{nm})$ & 4 \\
\hline
\end{tabular}

Table 5 Conditions of AES analysis

\begin{tabular}{ll}
\hline Instrument & $\begin{array}{l}\text { PHI instruments } \\
\text { Model-680 }\end{array}$ \\
\hline Electron beam energy $(\mathrm{kV})$ & 5 \\
Test area $(\mu \mathrm{m})$ & $333 \times 266$ \\
Depth of analysis $(\mathrm{nm})$ & $3-4$ \\
\hline
\end{tabular}

properties of a lubricant under boundary conditions with good repeatability. The friction coefficients of all the phosphonium salts were observed to be lower than that of BIMI-TFSA, as shown in Fig. 1. As we have reported previously, the pendulum friction test indicated that the friction coefficient of 1-alkyl-3-methylimidazolium salts decreased with an increase in the chain length of the alkyl group $[12,14]$. On the other hand, as shown in Fig. 2, the alkyl group appeared to have a slight effect on the friction coefficient of phosphonium salts. The addition of a benzyl substituent resulted in a slight increase in the friction coefficient. $\mathrm{Et}_{3} \mathrm{MeOEP}-\mathrm{TFSA}$ exhibited a considerably low friction coefficient as compared to that of $\mathrm{Et}_{2} \mathrm{MeMeOEN}$ TFSA. When the friction coefficients of phosphate salts such as Bu3MeP-MePhos or Bu4P-EtTPhos were compared to those of TFSA salts such as Bu3PMe-TFSA, it was observed that the phosphate anion (in the case of Bu3MeP-MePhos) afforded a slightly high friction coefficient to the phosphate salt whereas the thiophosphate anion (in the case of Bu4P-EtTPhos) afforded a low friction coefficient to the phosphate salt. These results indicate the effect of the anion on the tribological properties of phosphonium salts.

\subsection{Observation of Friction and Wear Using Ball-on-Flat-Type Test}

The results of the ball-on-flat-type test also showed that the friction coefficient of phosphonium salts was lower than that of BMIM-TFSA; the only phosphonium salt that was an exception to this was the $\mathrm{Et}_{3} \mathrm{MeOEP}-\mathrm{TFSA}$ (Fig. 3). The wear width on the ball and flat were also measured after the tribo-test was conducted (Fig. 4). The wear by (thio)phosphate salts was lower than that by TFSA salts. 
Fig. 1 Structure-friction relationship (pendulum test)

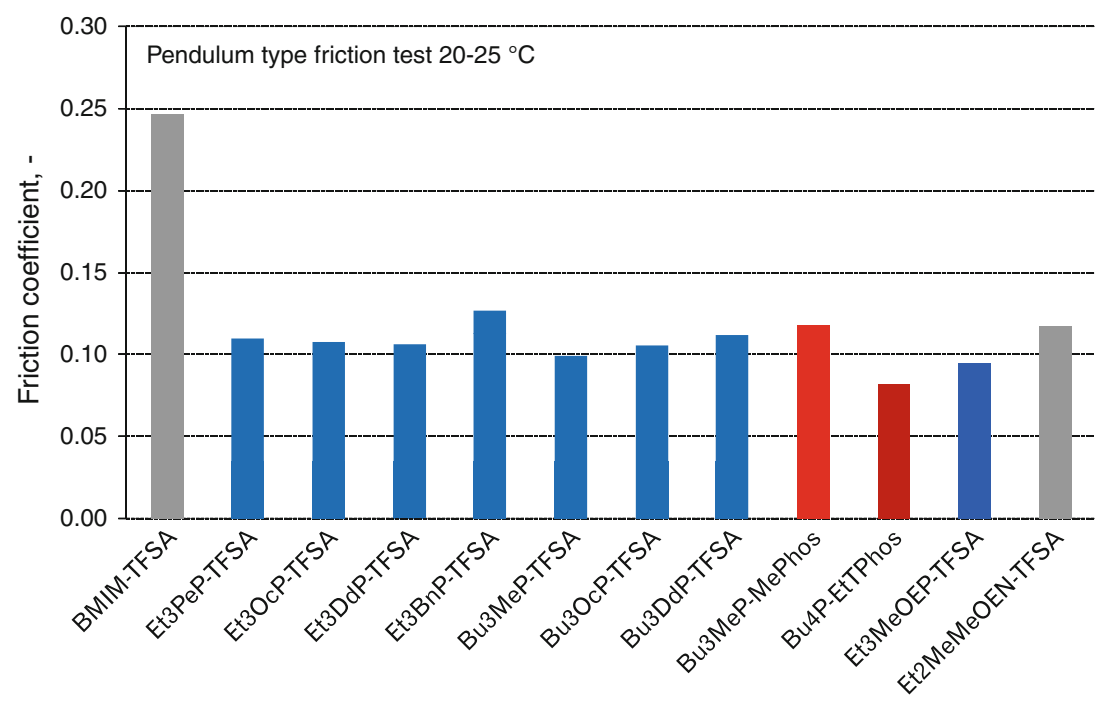

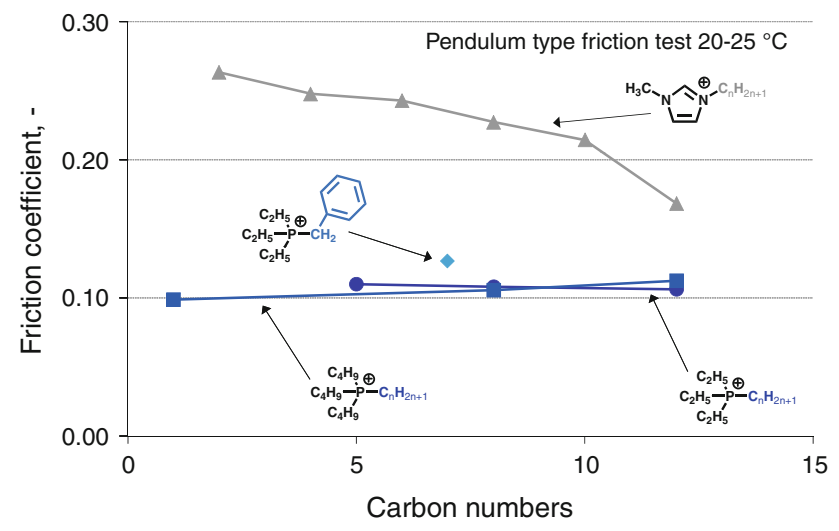

Fig. 2 Structure-friction relationship for TFSA salts (pendulum test)

We are interested in the surface chemistry involved in the tribological process. Therefore, we selected $\mathrm{Bu}_{3} \mathrm{PMe}-$ TFSA, $\mathrm{Bu}_{3} \mathrm{MeP}-\mathrm{MePhos}$, and $\mathrm{Bu}_{4} \mathrm{P}-\mathrm{EtTPhos}$ for further investigations. The tribological properties of the selected salts were evaluated as functions of the applied load using a ball-on-flat-type tester. We determined the relationship between the chemical structure and the friction-reducing properties (Fig. 5). For a load of $40 \mathrm{~N}$, all the phosphonium salts exhibited a friction coefficient of approximately 0.08 and the 1,3-dialkylimidazolium salt exhibited a higher friction coefficient of 0.095 . For a load of $60 \mathrm{~N}$, only the (thio)phosphate salts exhibited a low friction coefficient (approximately 0.08). The TFSA salts, i.e., both the BMIM salt and the $\mathrm{R}_{4} \mathrm{P}$ salt, exhibited a high friction coefficient of 0.09. These results indicate that cationic moiety is responsible for the friction coefficient for a load of $40 \mathrm{~N}$, while anionic moieties are responsible for the friction coefficient for a load of $60 \mathrm{~N}$. For a load of 10 and $20 \mathrm{~N}$, both the anionic and the cationic moieties influence the friction coefficient. Consequently, in the case of cationic moieties, the friction coefficient decreases in the following
Fig. 3 Structure-friction relationship (ball-on-flat-type test for a load of $20 \mathrm{~N}$ )

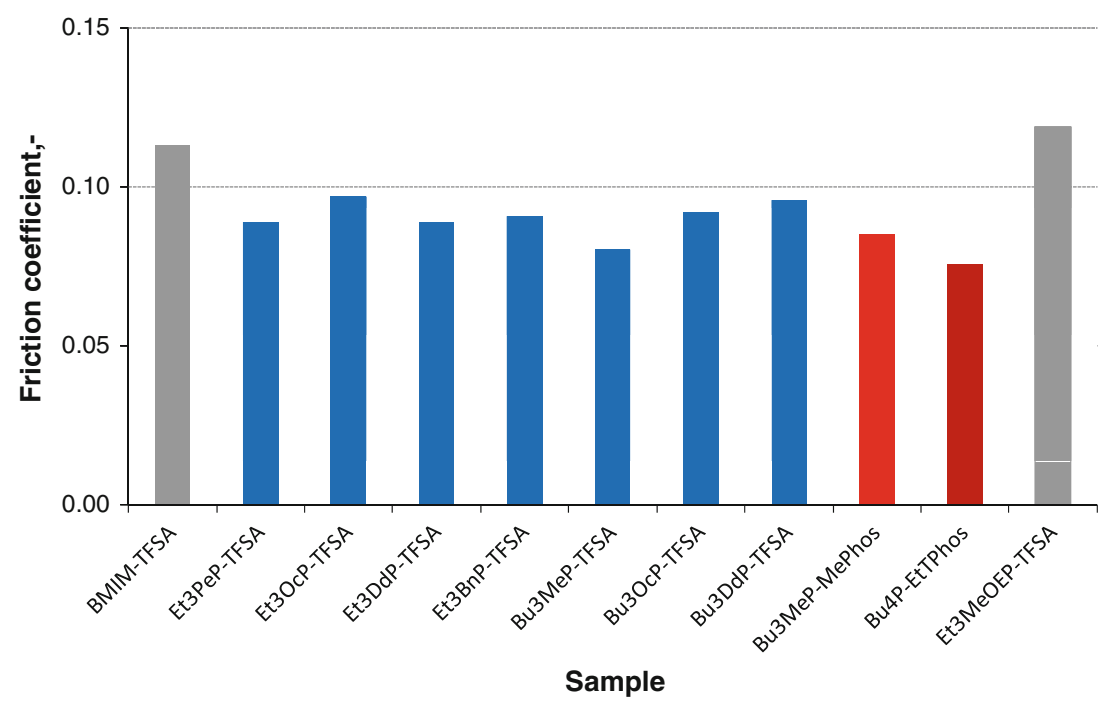


Fig. 4 Structure-wear relationship (ball-on-flat-type test for a load of $20 \mathrm{~N}$ )

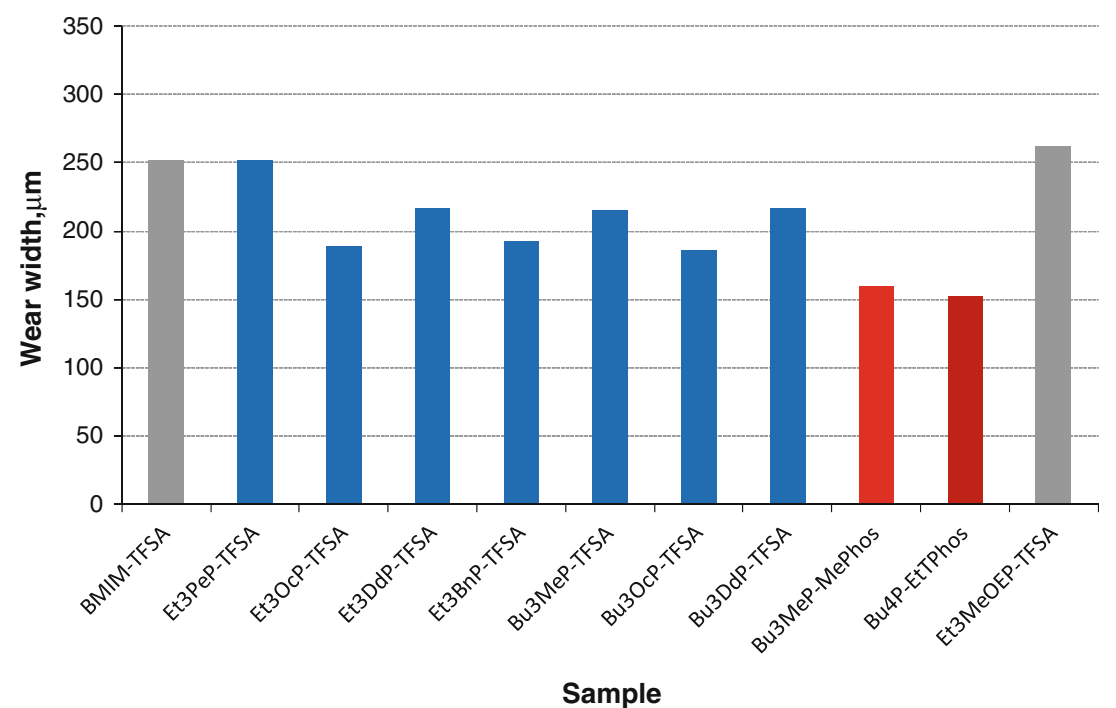

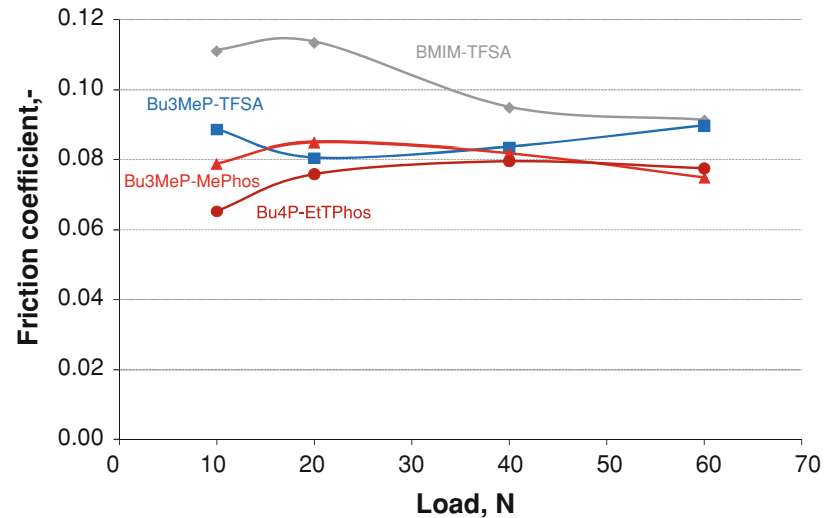

Fig. 5 Effects of load on friction (ball-on-flat-type test)

order: 1,3-dialkylimidazolium $>$ tetraalkylphosphonium. Further, in the case of anionic moieties, it decreases in the following order: TFSA $>$ phosphate $>$ thiophosphate.

The anionic moieties clearly have an effect on the wear properties of the salts. The wear caused by the (thio)phosphate salts was considerably lower than that caused by the TFSA salts (Fig. 6). The presence of the phosphonium cation contributed to the reduction in the wear caused by the TFSA salt. For a load of 10-40 N, the width of the wear caused by $\mathrm{Bu}_{3} \mathrm{PMe}-\mathrm{TFSA}$ was lower than that caused by BMIM-TFSA. However, for a load of $60 \mathrm{~N}$, the phosphonium cation appeared to have no effect on wear reduction. These results indicate that the anionic moieties are greatly responsible for the wear. The cationic moieties affect the wear reducing properties under low-load conditions.

\subsection{Surface Chemistry}

Figure 7 shows the elemental mapping on the flat specimen including inside and outside the wear track. We found that

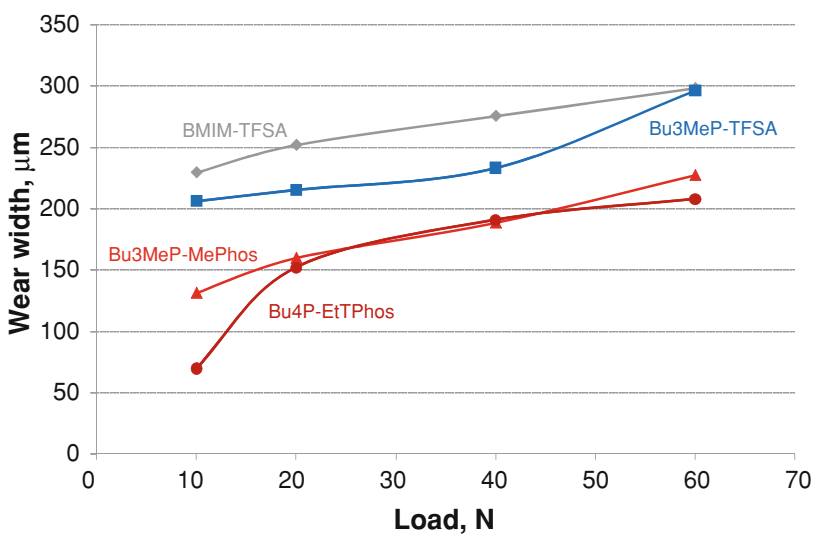

Fig. 6 Effects of load on wear (ball-on-flat-type test)

the concentration of oxygen and phosphorus inside the wear track was higher than that outside it. The presence of phosphate inside the wear track was confirmed by the XPS spectrum, which showed the binding energy of $P 2 p$ at $133 \mathrm{eV}$ (Fig. 8). These results indicate that the tribochemical reaction of $\mathrm{Bu}_{3} \mathrm{PMe}-\mathrm{MePhos}$ yielded a boundary film composed of iron phosphate. It is well recognized that the phosphate boundary film is instrumental in improving the tribological properties [27]. Sulfoxides, sulphides, and phosphate were detected on the surface rubbed with $\mathrm{Bu}_{4} \mathrm{P}$ EtTPhos (Fig. 9). Sulphides are also known as key compounds that improve tribological properties [28]. The (thio)phosphate salts, $\mathrm{Bu}_{3} \mathrm{PMe}-\mathrm{MePhos}$ and $\mathrm{Bu}_{4} \mathrm{P}-\mathrm{EtT}$ Phos, are analogous in chemical structure to conventional antiwear additives such as tricresyl phosphates and zinc dialkyldithiophospates. Therefore, the tribological properties and surface chemistry of (thio)phosphate salts are closely related to those of conventional lubricants.

In contrast to the observations of the elemental mapping on the flat specimen rubbed with $\mathrm{Bu}_{3} \mathrm{PMe}-\mathrm{MePhos}$, no 
Fig. 7 AES chemical mapping of rubbed surface for a load of $60 \mathrm{~N}\left[\mathrm{Bu}_{3} \mathrm{MeP}-\mathrm{MePhos}\right]$
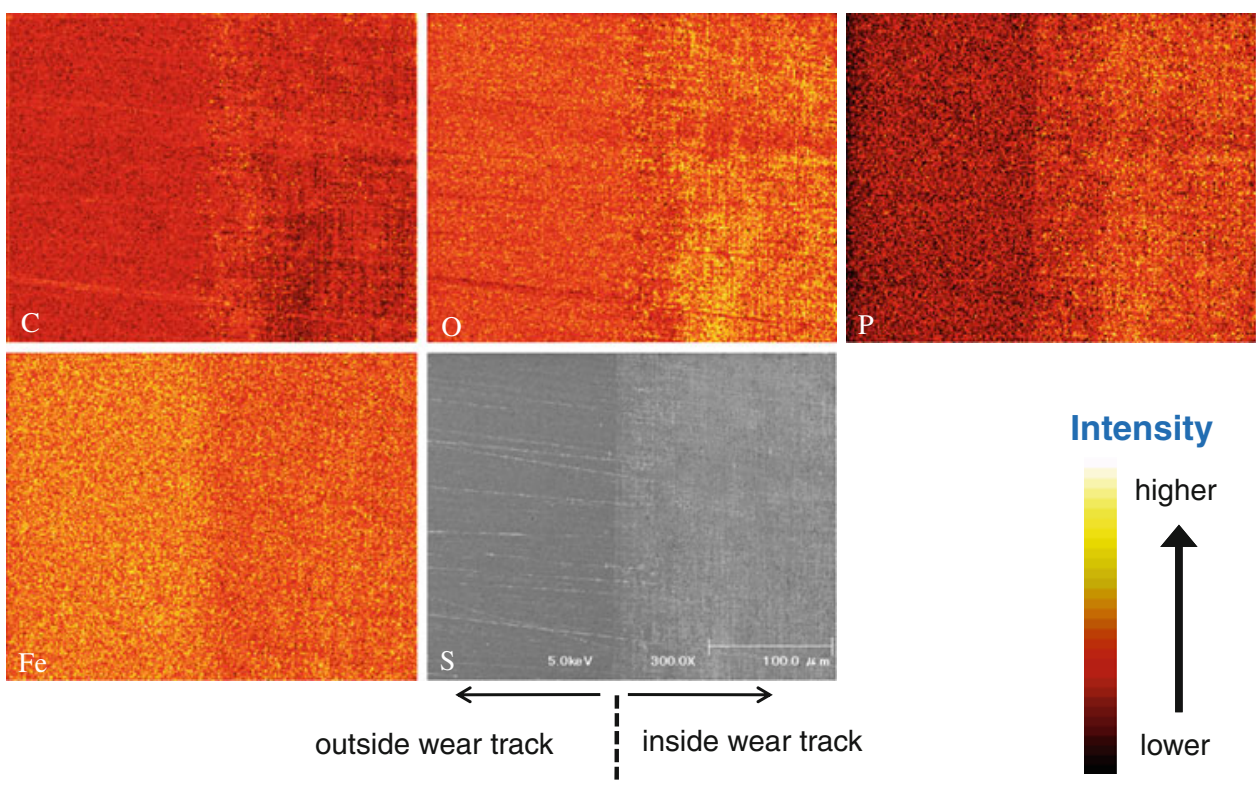

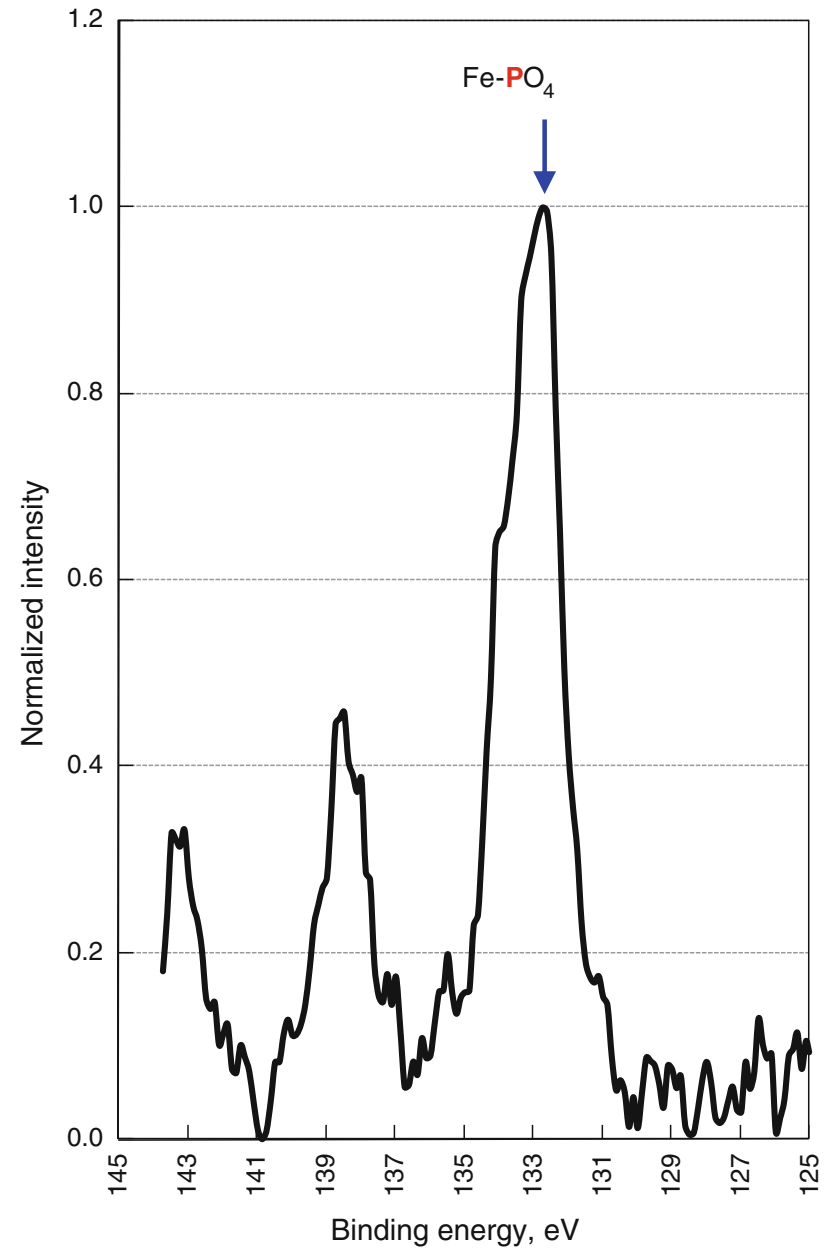

Fig. 8 XPS spectrum of rubbed surface for a load of $60 \mathrm{~N}\left[\mathrm{Bu}_{3} \mathrm{MeP}-\right.$ MePhos] detectable phosphorus was found inside the wear track in the case of the specimen rubbed with the TFSA salt $\left(\mathrm{Bu}_{3} \mathrm{PMe}-\mathrm{TFSA}\right)$ (Fig. 10). These results indicate that anionic moieties are major reactants in the tribochemical reactions under these conditions. The tribochemical reaction of TFSA salts has been reported to yield metal fluorides on rubbed surfaces [29]. In fact, we detected both organic fluoride $(\mathrm{C}-\mathrm{F}$ at the binding energy of $688 \mathrm{eV})$ and inorganic fluoride ( $\mathrm{Fe}-\mathrm{F}$ at the binding energy of $684 \mathrm{eV}$ ) on the surface rubbed with $\mathrm{Bu}_{3}$ PMe-TFSA (Fig. 11). The former is the TFSA adsorbed on the surface and the latter is the TFSA reacted with iron on the surface. The ratio of the adsorbed fluoride to the reacted fluoride changes with the change in the load applied in the tribo-test. In the case of a $20 \mathrm{~N}$ load, a greater proportion of adsorbed TFSA was observed on the rubbed surface. On the other hand, in the case of a $60 \mathrm{~N}$ load, a greater proportion of reacted TFSA was observed on the rubbed surface. It is well understood that activation energy sufficient for the tribochemical reaction of TFSA was provided at a higher load.

Detectable amounts of phosphate as well as sulfoxides were observed on the surface rubbed with $\mathrm{Bu}_{3} \mathrm{MeP}-\mathrm{TFSA}$ (Fig. 12). The presence of the phosphate indicates that the tribochemical reaction of the cationic moiety occurred during the tribo-test [22]. Both adsorbed TFSA and reacted TFSA contained sulfoxide moieties. Therefore, the presence of both these species is possible.

When the specimen was rubbed with the reference sample (BMIM-TFSA), metal fluorides, sulfoxides, and sulphides were detected on the rubbed surfaces (Fig. 13). A careful study of the fluorine XPS spectra shown in Figs. 11 and 13 indicates the differences between the tribochemical 
Fig. 9 XPS spectra of rubbed surface for a load of $20 \mathrm{~N}$ [Bu ${ }_{4} \mathrm{P}-$ EtTPhos $]$

Fig. 10 AES chemical mapping of rubbed surface for a load of $60 \mathrm{~N}\left[\mathrm{Bu}_{3} \mathrm{MeP}-\mathrm{TFSA}\right]$
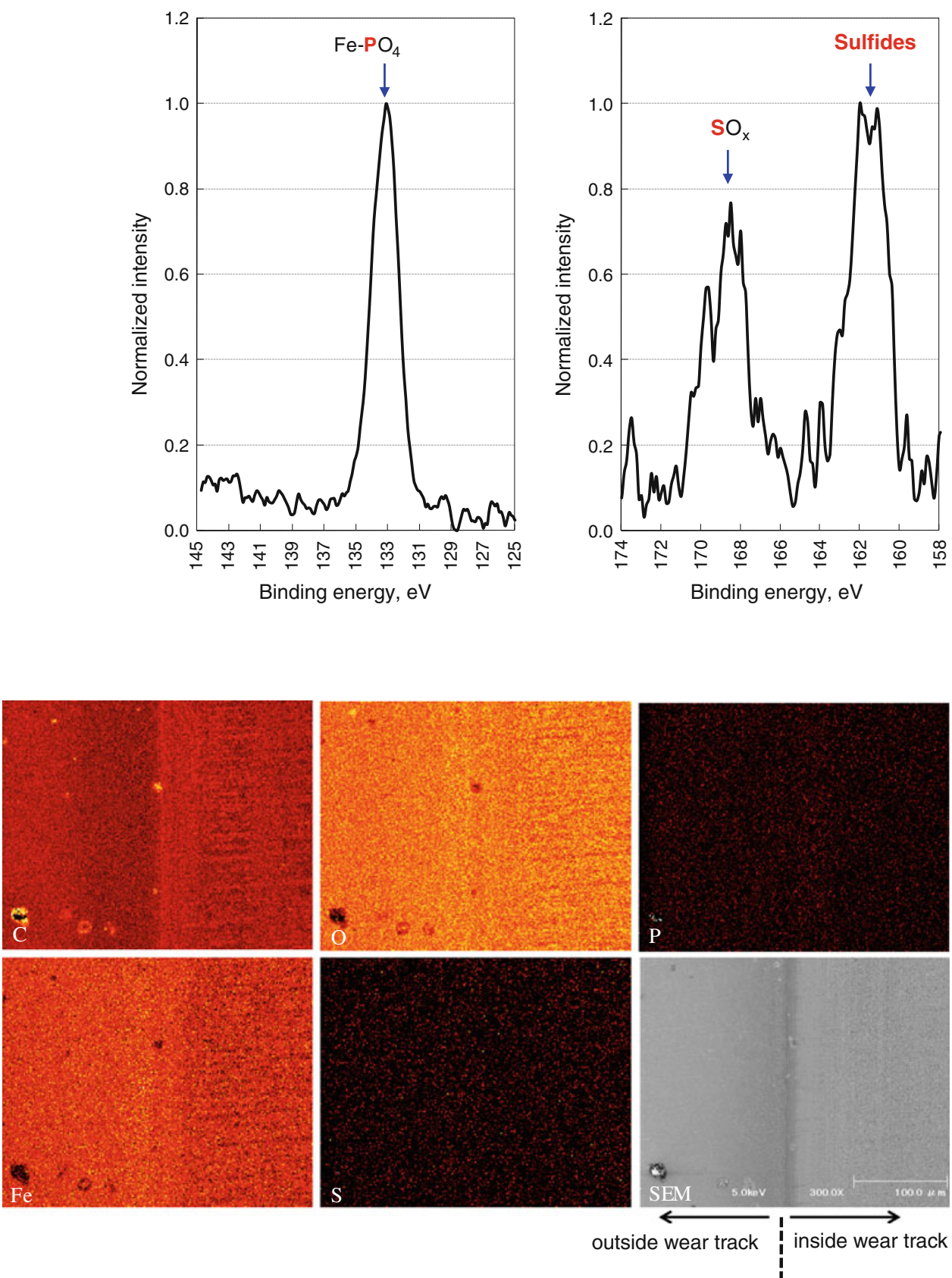

reactions of $\mathrm{Bu}_{3} \mathrm{MeP}-\mathrm{TFSA}$ and $\mathrm{BMIM-TFSA}$. In the case of a $20 \mathrm{~N}$ load, a greater proportion of adsorbed TFSA was observed in the case of $\mathrm{Bu}_{3} \mathrm{MeP}-\mathrm{TFSA}$, whereas a greater proportion of reacted TFSA was observed in the case of BMIM-TFSA. The sulphur XPS spectra shown in Figs. 12 and 13 also suggest that the tribochemical reaction of the anions in BMIM-TFSA. A considerable amount of sulphide was detected on the surface rubbed with BMIM-TFSA. However, no sulphides - if any exist - were detected on the surface rubbed with $\mathrm{Bu}_{3} \mathrm{MeP}-\mathrm{TFSA}$. From these results, it can be concluded that for a $20 \mathrm{~N}$ load, the phosphonium cation reduced the tribochemical reaction of the TFSA anion to some extent. However, the cation did not reduce the reaction of the anion for a load of $60 \mathrm{~N}$. As shown in Table 6, no phosphorus was detected on the rubbed surface. These results indicate that these conditions were more favourable to the reaction of the anion than the reaction of the cation.

\subsection{Lubrication Mechanism}

The results of the ball-on-flat-type test reveal the effects of the anionic moieties on friction and wear. The tribological properties of (thio)phosphate salts were observed to be 
Fig. 11 F1s XPS spectra of rubbed surface $\left[\mathrm{Bu}_{3} \mathrm{MeP}-\mathrm{TFSA}\right]$
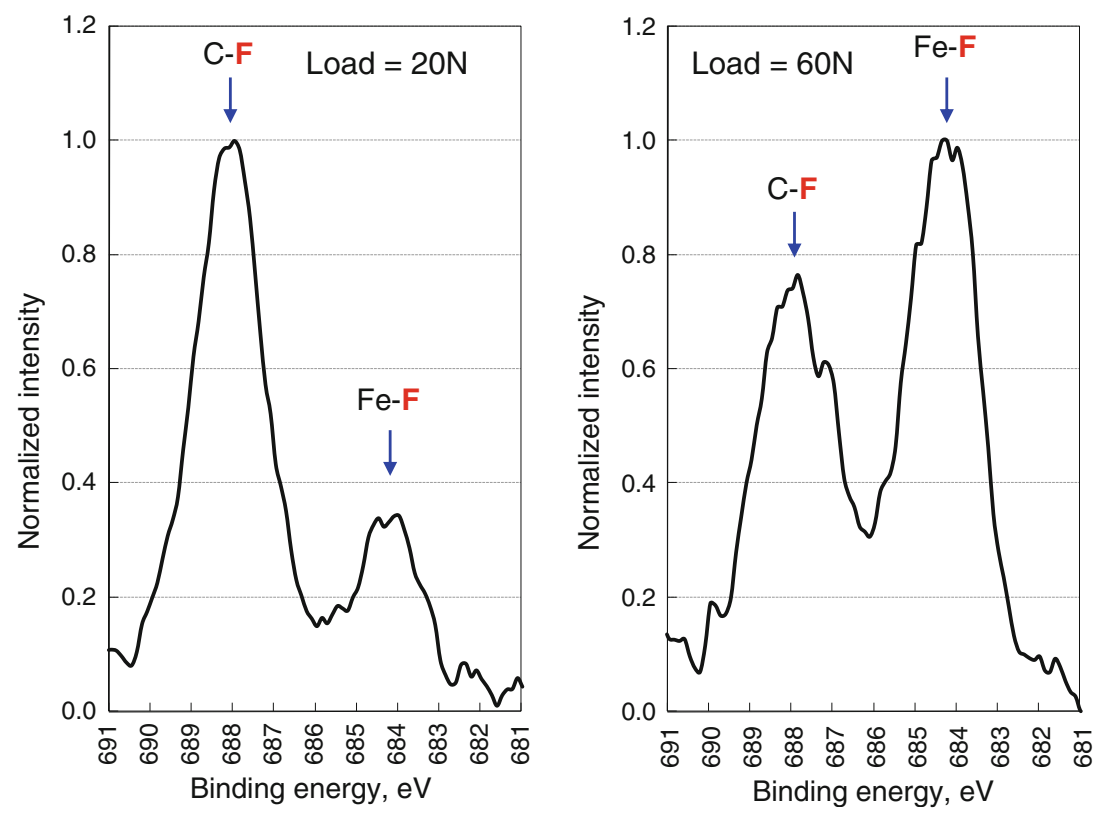

Fig. 12 XPS spectra of rubbed surface for a load of $20 \mathrm{~N}$ [ $\left.\mathrm{Bu}_{3} \mathrm{MeP}-\mathrm{TFSA}\right]$

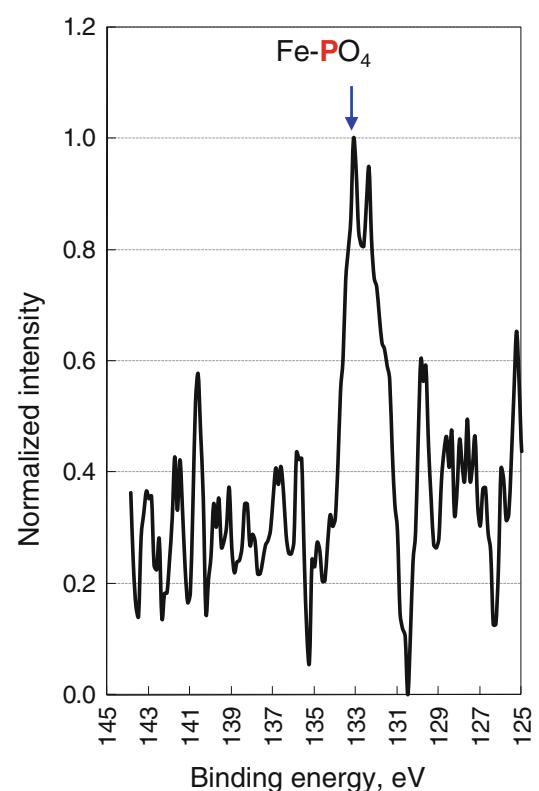

better than those of TFSA salts (Figs. 5, 6). As mentioned above, the reaction of the (thio)phosphate salts yielded a phosphate-containing boundary film and the reaction of the TFSA salts yielded a fluoride-containing boundary film. From these results, it can be concluded that phosphate films exhibit better tribological properties than fluoride films. For a load of $20 \mathrm{~N}$, the tribological properties of $\mathrm{Bu}_{3} \mathrm{MeP}-$ TFSA, which contains a phosphorus cation and a fluorine anion, were observed to be intermediate between those of BMIM-TFSA and $\mathrm{Bu}_{3}$ MeP-MePhos. The reaction of $\mathrm{Bu}_{3} \mathrm{MeP}-\mathrm{TFSA}$ yielded a boundary film that comprised both phosphate and fluoride and contained an adsorbed
TFSA on its uppermost surface. These results indicate that both phosphate and fluoride ions are responsible for the tribological properties of the salt. For a load of $60 \mathrm{~N}$, $\mathrm{Bu}_{3}$ MeP-TFSA yielded a fluoride film and no detectable phosphate film. Under these conditions, the tribological properties of $\mathrm{Bu}_{3} \mathrm{MeP}-\mathrm{TFSA}$ and BIMI-TFSA were quite similar. We wish to propose a model of the boundary film on the basis of the similarities in the tribological properties and surface chemistry of these salts (Fig. 14).

It has been stated that the tribological properties of iron fluorides are better than those of naked metal surfaces [30, 31]. Despite the fact that the iron fluorides possess physical 
Fig. 13 XPS spectra of rubbed surface at $20 \mathrm{~N}$ [BMIM-TFSA]

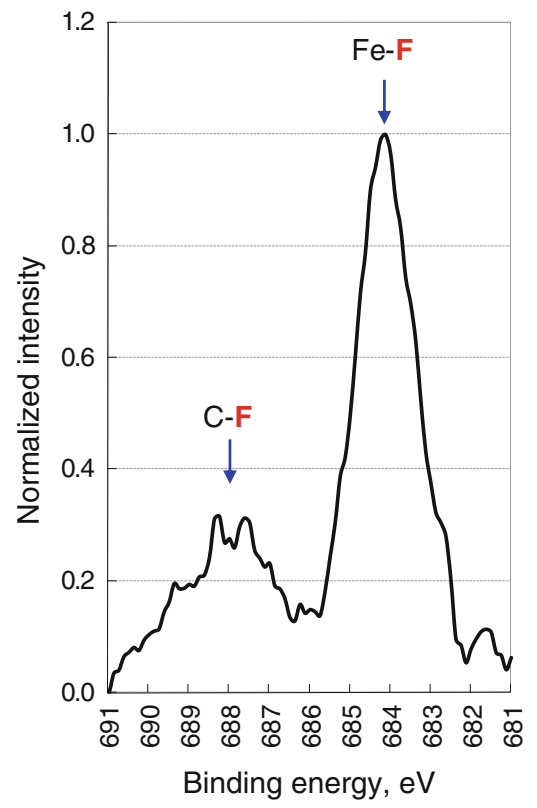

Table 6 Elemental concentration on surface obtained by XPS analysis

\begin{tabular}{llllll}
\hline Sample & Load $(\mathrm{N})$ & \multicolumn{4}{c}{ Element concentration (at.\%) } \\
\cline { 3 - 6 } & & $\mathrm{C}$ & $\mathrm{F}$ & $\mathrm{P}$ & $\mathrm{S}$ \\
\hline Bu $_{3}$ MeP-MePhos & 60 & 34 & nd & 4.3 & nd \\
Bu $_{3}$ MeP-TFSA & & 36 & 3.0 & nd & 2.5 \\
& & 25 & 436 & 0.40 & 4.1 \\
Bu $_{4}$ P-EtTPhos & 20 & 29 & nd & 3.3 & 0.80 \\
BMIM-TFSA & & 36 & 2.4 & nd & 2.4 \\
\hline
\end{tabular}

nd not detected

properties that are conducive to better tribological properties, they have certain disadvantages from a chemical perspective. The hydrolysis of iron fluorides yields iron hydroxides and iron oxides and hence results in the rusting of iron. Iron fluorides are one of the Lewis acids that catalyze the degradation of lubricants [29, 32]. Therefore, a decrease in the tribochemical reaction of the TFSA anion appears to be instrumental in improving the tribological properties of RT-ILs.

The contact stress applied in the pendulum test $(1.1 \mathrm{GPa})$ was lower than that applied in the ball-on-flattype test for a load of $20 \mathrm{~N}$ (1.3 GPa). Therefore, it was assumed that the tribochemical reaction of TFSA was inhibited during the pendulum friction test, and hence, the effect of the phosphate boundary film on friction was possibly greater in the pendulum friction test. This is probably the reason for the low friction coefficient of phosphonium salts as compared to that of 1,3-dialkylimidazolium salts. However, the surface analyses of the surface rubbed during the pendulum friction test were difficult

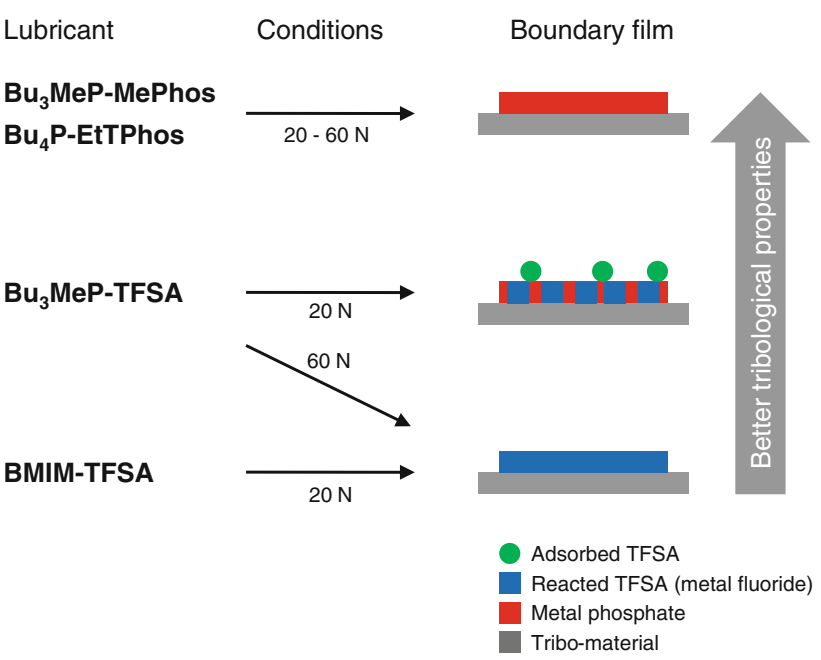

Fig. 14 Proposed model of boundary film derived from phosphonium salts

to conduct because no measurable wear scars were obtained in this tribo-test.

\section{Conclusions}

(1) The tribological properties of bis(trifluoromethanesulfonyl)amide salts of tetraalkylphosphoniumderived room temperature ionic liquids were better than those of 1,3-dialkylimidazolium-derived ones. Alkyl groups, with carbon numbers ranging from 2 to 12 , present in the phosphonium cation have a slight effect on the tribological properties of the salt.

(2) The tribochemical reactions of the phosphonium cation and bis(trifluoromethanesulfonyl)amide anion 
yielded a phosphate boundary film and a fluoride boundary film, respectively. A mixture of these films was formed during a tribo-test under low-load conditions; the formation of the fluoride film was predominant under these conditions. The decrease in the tribochemical reaction of bis(trifluoromethanesulfonyl)amide due to a tetraalkylphosphonium cation was analytically confirmed.

(3) The tribological properties of tetraalkylphosphonium salts of dialkylphosphate and those of tetraalkylphosphonium salts of dialkyldithiophosphate were considerably better than those of tetraalkylphosphonium salts of bis(trifluoromethanesulfonyl)amide. The tribochemical reactions of dialkylphosphate and dialkyldithiophosphate yielded a phosphate boundary film. This lubrication mechanism is closely related to that of conventional antiwear additives such as alkylphosphate and zinc dialkyldithiophosphate.

Acknowledgments This study was supported by a Grant-in-Aid for Scientific Research on Priority Areas, Science of Ionic Liquids (Grant Nos. 18045003 and 20031001) from the Ministry of Education, Culture, Sports, Science and Technology, Japan. The authors are grateful to Nippon Chemical Industrial Co., Ltd., for providing us with the phosphonium salts.

\section{References}

1. Wilkes, J.S., Zaworotko, M.J.: Air and water stable 1-ethyl-3methylimidazolium based ionic liquids. Chem. Commun. 965967 (1992)

2. Seddon, K.R.: Room-temperature ionic liquids: neoteric solvents for clean catalysis. Kinet. Catal. 37, 693-697 (1996)

3. Welton, T.: Room-temperature ionic liquids. Solvents for synthesis and catalysis. Chem. Rev. 99, 2071-2083 (1999)

4. Earle, M.J., Seddon, K.R.: Ionic liquids. Green solvents for the future. Pure Appl. Chem. 72, 1391-1398 (2000)

5. Wilkes, J.S.: A short history of ionic liquids? From molten salts to neoteric solvents. Green Chem. 4, 73-80 (2002)

6. Rogers, R.D., Seddon, K.R.: Ionic liquids-solvents of the future? Science 302, 792-793 (2003)

7. Torimoto, T., Tsuda, T., Okazaki, K., Kuwabata, S.: New frontiers in materials science opened by ionic liquids. Adv. Mater. 22, 1196-1221 (2010)

8. Ye, C., Liu, W., Chen, Y., Yu, L.: Room-temperature ionic liquids: a novel versatile lubricant. Chem. Commun. 2244-2245 (2001)

9. Minami, I.: Ionic liquids in tribology. Molecules 14, 2286-2305 (2009)

10. Zhou, F., Liang, Y., Liu, W.: Ionic liquid lubricants: designed chemistry for engineering applications. Chem. Soc. Rev. 38, 2590-2599 (2009)

11. Bermudez, M.D., Jimenez, A.E., Sanes, J., Carrion, F.J.: Ionic liquids as advanced lubricant fluids. Molecules 14, 2888-2908 (2009)

12. Kamimura, H., Kubo, T., Minami, I., Mori, S.: Effect and mechanism of additives for ionic liquids as new lubricants. Tribol. Int. 40, 620-625 (2007)
13. Minami, I., Kita, M., Kubo, T., Nanao, H., Mori, S.: The tribological properties of ionic liquids composed of trifluorotris(pentafluoroethyl) phosphate as a hydrophobic anion. Tribol. Lett. 30, 215-223 (2008)

14. Kamimura, H., Chiba, T., Watanabe, N., Kubo, T., Nanao, H., Minami, I., Mori, S.: Effects of carboxylic acids on wear and friction reducing properties for alkylimidazolium-derived ionic liquids. Tribol. Online 1, 40-43 (2006)

15. Minami, I., Kamimura, H., Mori, S.: Thermo-oxidative stability of ionic liquids as lubricating fluids. J. Synth. Lubr. 24, 135-147 (2007)

16. Canter, N.: Evaluating ionic liquids as potential lubricants. Tribol. Lubr. Technol. 61, 15-17 (2005)

17. Bradaric, C.J., Downard, A., Kennedy, C., Robertson, A.J., Zhou, Y.: Industrial preparation of phosphonium ionic liquids. Green Chem. 5, 143-152 (2003)

18. Tsunashima, K., Sugiya, M.: Physical and electrochemical properties of room temperature ionic liquids based on quaternary phosphonium cations. Electrochemistry 75, 734-736 (2007)

19. Tsunashima, K., Sugiya, M.: Physical and electrochemical properties of low-viscosity phosphonium ionic liquids as potential electrolytes. Electrochem. Commun. 9, 2353-2358 (2007)

20. Yu, G., Yan, S., Zhou, F., Liu, X., Liu, W., Liang, Y.: Synthesis of dicationic symmetrical and asymmetrical ionic liquids and their tribological properties as ultrathin films. Tribol. Lett. 25, 197-205 (2007)

21. Weng, L.J., Liu, X.Q., Liang, Y.M., Xue, Q.J.: Effect of tetraalkylphosphonium based ionic liquids as lubricants on the tribological performance of a steel-on-steel system. Tribol. Lett. 26, 11-17 (2007)

22. Weng, L.J., Liu, X.Q., Liang, Y.M., Xue, Q.J.: Effect of tetraalkylphosphonium based ionic liquids as lubricants on the tribological performance of a steel-on-steel system. Tribol. Lett. 26(1), 11-17 (2007)

23. Liu, X.Q., Zhou, F., Liang, Y.M., Liu, W.M.: Tribological performance of phosphonium based ionic liquids for an aluminumon-steel system and opinions on lubrication mechanism. Wear 261, 1174-1179 (2006)

24. Jimenez, A.E., Bermudez, M.D.: Imidazolium ionic liquids as additives of the synthetic ester propylene glycol dioleate in aluminium-steel lubrication. Wear 265, 787-798 (2008)

25. Itoh, T., Watanabe, N., Inada, K., Ishioka, A., Hayase, S., Kawatsura, M., Minami, I., Mori, S.: Design of alkylsulfate ionic liquids for lubricants. Chem. Lett. 38, 64-65 (2009)

26. Kyropoulos, S., Shobert, E.I.: A simple method for measuring the coefficient of nonviscous friction of thin lubricating layers. Rev. Sci. Instrum. 8, 151-158 (1937)

27. Forbes, E.S.: Antiwear and extreme pressure additives for lubricants. Tribology 3, 145-152 (1970)

28. Forbes, E.S.: The load-carrying action of organo-sulphur compounds a review. Wear 15, 87-96 (1970)

29. Phillips, B.S., John, G., Zabinski, J.S.: Surface chemistry of fluorine containing ionic liquids on steel substrates at elevated temperature using Mossbauer spectroscopy. Tribol. Lett. 26, 85-91 (2007)

30. Choa, S.H., Ludema, K.C., Potter, G.E., DeKoven, B.M., Morgan, T.A., Kar, K.K.: A model for the boundary film formation and tribological behavior of a phosphazene lubricant on steel. Tribol. Trans. 38, 757-768 (1995)

31. Zhu, J., Chu, R., Meng, X.: Chemical structure of phosphazenes in relation to the tribological properties of a steel-on-steel system. Lubr. Sci. 21, 103-109 (2009)

32. Carre, D.J., Markowitz, J.A.: The reaction of perfluoroalkylether oil with $\mathrm{FeF}_{3}, \mathrm{AlF}_{3}$ and $\mathrm{AlCl}_{3}$ at elevated temperatures. ASLE Trans. 28, 40-46 (1985) 